\title{
Cross-Sectional Inverse Associations of Obesity and Fat Accumulation Indicators with Testosterone in Non-Diabetic Aging Men
}

\author{
Iwona Rotter ${ }^{1,+}$, Aleksandra Rył 1,+ (D), Katarzyna Grzesiak ${ }^{2}$ (D), Aleksandra Szylińska ${ }^{1, *}$, \\ Wioletta Pawlukowska ${ }^{1}$, Anna Lubkowska ${ }^{3}$, Olimpia Sipak-Szmigiel ${ }^{4}$, Krzysztof Pabisiak ${ }^{5}$ \\ and Maria Laszczyńska ${ }^{2}$ \\ 1 Department of Medical Rehabilitation and Clinical Physiotherapy, Pomeranian Medical University, \\ Żołnierska 54, 70-204 Szczecin, Poland; iwrot@wp.pl (I.R.); aleksandra.ryl@pum.edu.pl (A.R.); \\ wpawluko@pum.edu.pl (W.P.) \\ 2 Department of Histology and Developmental Biology, Pomeranian Medical University, Żołnierska 48, \\ 70-204 Szczecin, Poland; kasia.grzesiak302@gmail.com (K.G.); maria@laszczynska.pl (M.L.) \\ 3 Department of Physical Medicine and Functional Diagnostics, Pomeranian Medical University, \\ Żołnierska 54, 70-204 Szczecin, Poland; anna.lubkowska@pum.edu.pl \\ 4 Department of Obstetrics and Pathology of Pregnancy, Pomeranian Medical University in Szczecin, \\ Żołnierska 48, 71-210 Szczecin, Poland; olimpiasipak-szmigiel@wp.pl \\ 5 Department of Nephrology, Transplantology and Internal Medicine, Pomeranian Medical University, \\ Powstańców Wlkp. 72, 70-111 Szczecin, Poland; bkpn@pum.edu.pl \\ * Correspondence: aleksandra.szylinska@gmail.com; Tel.: +48-(91)-48-00-914 \\ $\dagger$ These authors contributed equally to this work.
}

Received: 22 April 2018; Accepted: 6 June 2018; Published: 8 June 2018

\begin{abstract}
Introduction/Objective: The aim of the study was to show which of the adipose tissue accumulation indicators correlate with testosterone disorders in non-diabetic aging men. Material and methods: 455 non diabetic men, recruited at primary care facilities, aged 50-75 participated in the study. The participants underwent anthropometric measurement and ELISA determination of total testosterone (TT), estradiol $\left(\mathrm{E}_{2}\right)$, dehydroepiandrosterone sulphate (DHEA-S), sex hormone binding protein (SHBG), and the determination of fasting glucose (FPG), high-density lipids cholesterol (HDL-Ch), and triacylglycerols (TAG) in serum. The following indicators were calculated: body mass index (BMI), waist-to-hip ratio (WHR), lipid accumulation product (LAP), and visceral adiposity index (VAI). Results: Men with testosterone deficiency syndrome (TDS) differed in each of the assessed obesity indices from those without TDS. All of the studied parameters correlated significantly negatively with TT concentration in blood serum, with VAI being the strongest predictor of TDS. It was shown that the threshold value at which the risk of TDS increased was $28.41 \mathrm{~kg} / \mathrm{m}^{2}$ for BMI, 1.58 for VAI, $104 \mathrm{~cm}$ for WC, and 37.01 for LAP. Conclusions: Indicators of fat accumulation that take into account biochemical parameters in assessing lipid metabolism are better markers of actual body fat deposition than indicators based solely on anthropometric measurements. Among them, VAI seems the most suitable biomarker of TDS in non-diabetic aging men.
\end{abstract}

Keywords: aging men; testosterone; indicators of fat accumulation; adiposity

\section{Introduction}

Numerous studies and meta-analyses indicate the existence of mutual relationships between low levels of testosterone (T) and obesity [1-4]. The content of adipose tissue is related to the concentration of androgen in men and affects the balance between androgens and estrogens. In 1999, Cohen presented 
the hypothesis of the hypogonadal-obesity cycle, which explained why the low concentration of $\mathrm{T}$ contributed to the accumulation of adipose tissue, and how the deposition of adipose tissue reduced the concentration of $\mathrm{T}$ [5]. According to that concept, $\mathrm{T}$ is aromatized in adipose tissue to 17- $\beta$ estradiol. High expression of aromatase in adipocytes leads to a reduction in circulating $\mathrm{T}$, which in turn leads to an increase in the number of adipocytes and the accumulation of adipose tissue, and so a further decrease in $\mathrm{T}$ levels.

The excess aromatase activity from increased adipocyte numbers in obese men results in the suppression of gonadotrophin-mediated $\mathrm{T}$ secretion, leading to progressive hypogonadism $[3,6]$. The pituitary gland, reacting to an increase in $E_{2}$ concentration, inhibits the formation of $T$ in the testes. A decreased $T$ concentration leads to the accumulation of triacylglycerols (TAG) in abdominal fat tissue and to visceral obesity $[7,8]$. Another factor influencing that process is the effect of negative feedback from the hypothalamic-pituitary axis on T concentration, which is also regulated via aromatase $[9,10]$.

Another factor that may be important in this process is the production of kisspeptins. These peptides, produced in the hypothalamus, modulate the secretory function of gonads and influence leptin concentration in the body. GNRH (Gonadotropin-releasing hormone) neurons in the hypothalamus possess specialized receptors for kisspeptins that produce receptors for leptin [11]. In the case of progressing obesity, adipocytes produce elevated amounts of leptin, and the hypothalamic-pituitary axis becomes resistant to leptin. Leptin also directly affects the Leydig cells in the testes, resulting in reduced production of testosterone [12].

The content and accumulation of adipose tissue, including visceral fat, can be assessed using bioimpedance, computed tomography or magnetic resonance, as well as indirectly using anthropometric measurements: BMI (body mass index), WHR (waist-hip ratio), WC (waist circumference), and indicators taking into account anthropometric measurements and biochemical parameters: LAP (lipid accumulation product) [13], VAI (visceral adiposity index) [14] and BAI (body adiposity index) [15].

The aim of the study was to show which of the indicators used in the assessment of overweight, obesity and the accumulation of adipose tissue is the best indicator of TDS (testosterone deficiency syndrome) in non-diabetic aging men. We assumed that the fat accumulation indicators that take into account biochemical parameters of lipid metabolism would be better markers of actual fat deposition in the body than those based only on anthropometric measurements. Thus, with the proven relationship between obesity and $\mathrm{T}$ concentration, they may be more useful in predicting hypogonadism in aging men.

\section{Material and Methods}

The study included 455 men aged between 50 and 75 who volunteered after receiving information about the course and purpose of the study from GPs from primary care facilities operating in the city of Szczecin (Poland). The study excluded patients suffering from diabetes and those in whom the glucose concentration was $>126 \mathrm{mg} / \mathrm{d}$; those undergoing oncological treatment; taking neuroleptics, antidepressants or steroids; those treated with testosterone; and people with liver and thyroid diseases, ascites and with hernia of linea alba or hernia within postoperative scars. Finally, 455 men were qualified for the study (mean age: 62.83 years \pm 6.57 ). Written informed consent was obtained from all participating subjects. This study was performed according to the guidelines of Bioethics Committee of the Pomeranian Medical University in Szczecin (KB-0012/159/12), which abides by the Helsinki Declaration on ethical principles for medical research involving human subjects. All men participating in the study were informed about the purpose and the course of the research.

The participants underwent anthropometric measurements: body mass, body height, and abdominal circumference. Body mass index (BMI) and WHR were calculated.

Blood was collected from the ulnar vein of fasting individuals between 7:30 am to 9:00 am. Blood was collected into tubes with a clotting activator and gel separator and then centrifuged. The serum was stored at $-70{ }^{\circ} \mathrm{C}$. 
In the serum, fasting plasma glucose (FPG), high-density cholesterol (HDL-Ch) and triacylglycerols (TAG) were determined using a spectrophotometric method using ready-made reagent kits (Biolabo, Aqua-Med, Łódź, Poland). Serum concentrations of hormones: total testosterone (TT), estradiol $\left(E_{2}\right)$, dehydroepiandrosterone sulphate (DHEA-S), and sex hormone binding protein (SHBG) were determined by ELISA using ready-made commercial reagent kits (DRG-MedTek, Warsaw, Poland). TDS syndrome was diagnosed according to the recommendations of the consensus of the International Society of Andrology (ISA), International Society for the Study of the Aging Male (ISSAM), European Association of Urology (EAU), the European Academy of Andrology (EAA), and the American Society of Andrology (ASA) [16]. Patients with TT below $2.5 \mathrm{ng} / \mathrm{mL}$ or between $2.5 \mathrm{ng} / \mathrm{mL}$ and $3.5 \mathrm{ng} / \mathrm{mL}$ in the presence of clinical symptoms assessed by the Morley questionnaire [17] were qualified for a TT-deficient group.

LAP was calculated using the formula: LAP $=[\mathrm{WC}(\mathrm{cm})-65] \times$ TAG $(\mathrm{mmol} / \mathrm{L})[13]$. VAI was calculated according to the formula: VAI $=\mathrm{WC}(\mathrm{cm}) /[39.68+(1.88 \times \mathrm{BMI})] \times[(\mathrm{TAG} / 1.03) \times$ (1.31/HDL-Ch)] [14].

\section{Statistical Analysis}

Statistical analysis was performed using Statistica 13 software (StatSoft, Inc., Tulsa, OK, USA). In the characteristics of the group, the basic statistics (mean, standard deviation, minimum and maximum) were performed, and the normality of the distribution was checked using a Shapiro-Wilk test. The differences between the groups were assessed by Mann-Whitney $U$ and Student's $t$-tests. Correlations between the analyzed quantitative variables were calculated using a Pearson correlation coefficient. A logistic regression was used to determine the values of odds ratios (OR) and $95 \%$ confidence intervals (CI) for qualitative variables. The level of significance was assumed at $p \leq 0.05$.

\section{Results}

Table 1 presents the parameters analyzed in all men participating in the study.

Table 1. Characteristics of the study group $(n=455)$.

\begin{tabular}{lcccc}
\hline Parameters & Mean & SD & Min & Max \\
\hline Age (years) & 62.83 & 6.57 & 50.00 & 75.00 \\
Height $(\mathrm{m})$ & 1.74 & 0.06 & 1.49 & 1.98 \\
Body weight $(\mathrm{kg})$ & 83.96 & 13.62 & 51.50 & 136.00 \\
BMI & 27.65 & 4.01 & 18.72 & 43.90 \\
VAI & 1.87 & 1.35 & 0.27 & 9.41 \\
WHR & 0.97 & 0.06 & 0.83 & 1.22 \\
WC $(\mathrm{cm})$ & 99.44 & 10.91 & 70.00 & 146.00 \\
LAP & 55.82 & 39.69 & 7.32 & 338.97 \\
TAG $(\mathrm{mmol} / \mathrm{L})$ & 1.54 & 0.78 & 0.43 & 6.65 \\
HDL-Ch $(\mathrm{mg} / \mathrm{dL})$ & 51.69 & 17.56 & 19.31 & 129.00 \\
FPG $(\mathrm{mg} / \mathrm{dL})$ & 90.33 & 18.54 & 57.60 & 126.00 \\
TT $(\mathrm{ng} / \mathrm{mL})$ & 4.05 & 1.71 & 0.09 & 10.15 \\
SHBG $(\mathrm{nmol} / \mathrm{L})$ & 43.44 & 22.08 & 2.58 & 192.00 \\
DHEA-S $(\mu \mathrm{gmL} / \mathrm{mL})$ & 1.14 & 0.90 & 0.01 & 6.57 \\
E $_{2}(\mathrm{pg} / \mathrm{mL})$ & 38.43 & 23.01 & 4.93 & 168.83 \\
\hline
\end{tabular}

SD—standard deviation, Min—minimum, Max—maximum, BMI—body mass index, VAI—visceral adiposity index, LAP—lipid accumulation product, WC — waist circumference, WHR-waist-hip ratio, TAG—triglyceride, HDL-Ch-high density lipoprotein, FPG—-fasting plasma glucose, TT-total testosterone, SHBG—sex hormone binding globulin, DHEA-S—dehydroepiandrosterone sulfate, $\mathrm{E}_{2}$ - estradiol.

TDS was diagnosed in $182(40 \%)$ men. Patients with TDS and those without TDS differed in each of the obesity indicators analyzed in the study (Table 2). The groups did not differ significantly in age. 
Table 2. Indicators of obesity and fat accumulation in the studied men vs testosterone concentration.

\begin{tabular}{|c|c|c|c|c|c|c|c|c|c|}
\hline \multirow{2}{*}{ Parameters } & \multicolumn{4}{|c|}{$\begin{array}{c}\text { Men without Testosterone } \\
\text { Deficiency Syndrome }(n=273)\end{array}$} & \multicolumn{4}{|c|}{$\begin{array}{c}\text { Men with Testosterone Deficiency } \\
\text { Syndrome }(n=182)\end{array}$} & \multirow[t]{2}{*}{$p$} \\
\hline & Mean & SD & Min & Max & Mean & SD & Min & $\operatorname{Max}$ & \\
\hline BMI & 26.68 & 3.58 & 20.01 & 42.28 & 28.98 & 4.04 & 20.02 & 41.32 & $<0.0001$ \\
\hline WHR & 0.99 & 0.06 & 0.84 & 1.22 & 0.97 & 0.06 & 0.83 & 1.14 & 0.354 \\
\hline VAI & 1.59 & 1.10 & 0.43 & 7.24 & 2.29 & 1.70 & 0.30 & 9.41 & $<0.0001$ \\
\hline WC & 97.39 & 9.87 & 75.00 & 133.00 & 103.93 & 11.31 & 79.00 & 146.00 & $<0.0001$ \\
\hline LAP & 46.34 & 32.57 & 7.36 & 231.02 & 73.02 & 54.22 & 12.47 & 338.97 & $<0.0001$ \\
\hline
\end{tabular}

SD—standard deviation, Min—minimum, Max-maximum, $p$-statistical significance, BMI—body mass index, WHR — waist-hip ratio, VAI—visceral adiposity index, LAP—lipid accumulation product, WC—-waist circumference.

Correlations between the concentration of selected hormones determined in the study and metabolic and anthropometric indicators were analyzed (Table 3). It was shown that each of the analyzed indicators correlated significantly with TT concentration in the patients' blood serum.

Table 3. Correlations between the concentrations of the selected hormones and the metabolic and anthropometric indicators.

\begin{tabular}{ccccccccc}
\hline \multirow{2}{*}{ Parameters } & \multicolumn{2}{c}{ TT } & \multicolumn{2}{c}{ SHGB } & \multicolumn{2}{c}{ DHEA-S } & \multicolumn{2}{c}{ E $_{\mathbf{2}}$} \\
\cline { 2 - 9 } & $\mathbf{P}$ & $\boldsymbol{p}$ & $\mathbf{P}$ & $\boldsymbol{p}$ & $\mathbf{P}$ & $\boldsymbol{p}$ & $\mathbf{P}$ & $\boldsymbol{p}$ \\
\hline BMI & -0.281 & $<0.001$ & 0.058 & 0.218 & -0.085 & 0.070 & 0.035 & 0.460 \\
WHR & -0.317 & $<0.001$ & 0.009 & 0.886 & -0.122 & 0.049 & 0.122 & 0.051 \\
VAI & -0.238 & $<0.001$ & 0.020 & 0.663 & -0.014 & 0.759 & 0.029 & 0.539 \\
WC & -0.280 & $<0.001$ & 0.003 & 0.951 & -0.095 & $0.043^{*}$ & 0.058 & 0.215 \\
LAP & -0.264 & $<0.001$ & 0.009 & 0.841 & -0.034 & 0.467 & 0.042 & 0.373 \\
\hline
\end{tabular}

BMI—body mass index, WHR—waist-hip ratio, VAI—visceral adiposity index, LAP—lipid accumulation product, WC-waist circumference, TT-total testosterone, SHBG-sex hormone binding globulin, DHEA-S-dehydroepiandrosterone sulfate, $\mathrm{E}_{2}$ - estradiol, P-Pearson's linear correlation coefficient, $p$-statistical significance.

WC was the only indicator showing a significant negative correlation with one of the analyzing hormone, DHEA-S.

ROC curves were analyzed by setting cut-off points for each of the analyzed indicators (Figure 1). The threshold value at which the risk of TDS increased was $28.41 \mathrm{~kg} / \mathrm{m}^{2}$ for BMI, 1.58 for VAI, $104 \mathrm{~cm}$ for WC, and 37.01 for LAP. 
A

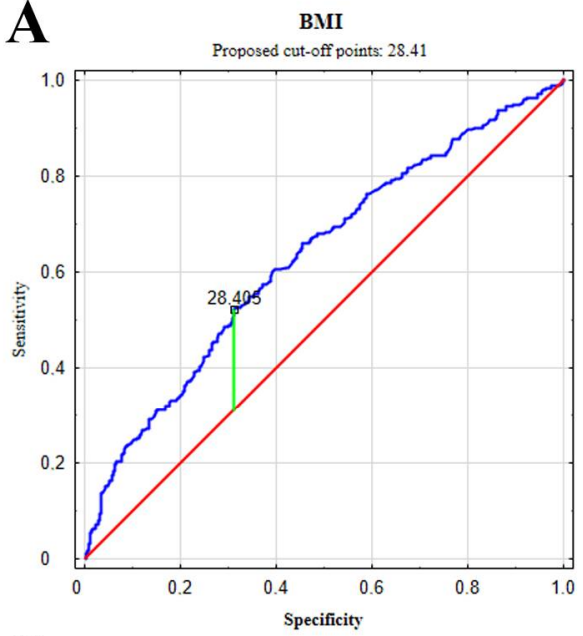

C

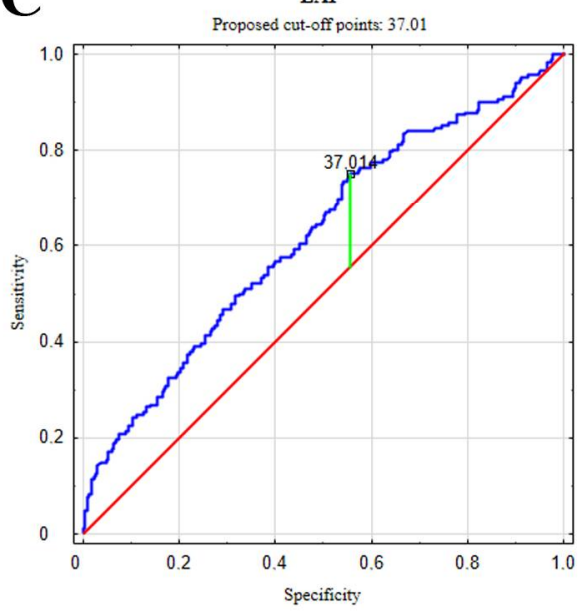

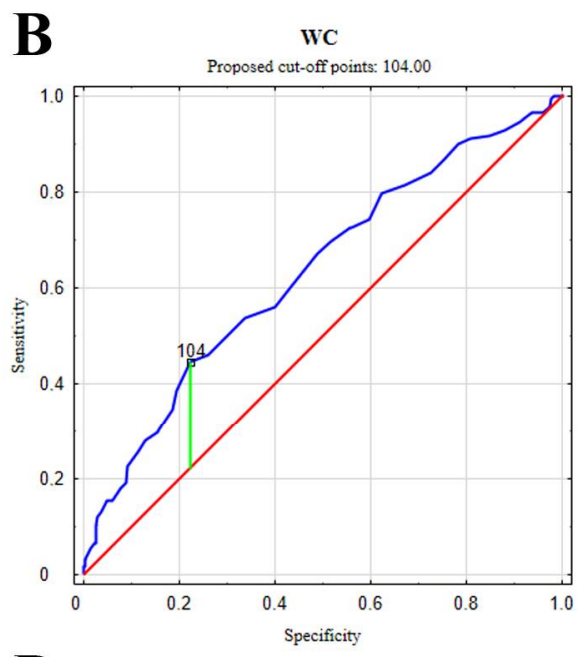

D

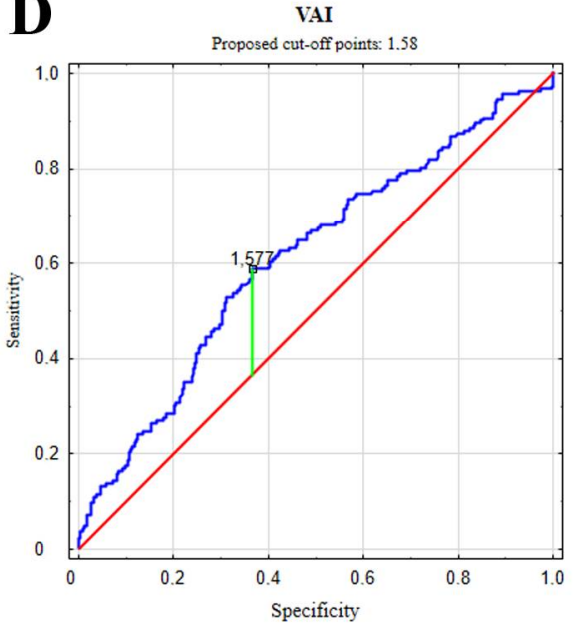

Figure 1. ROC curves. Cut-off points for the selected indicators of adiposity against testosterone levels: blue lines-The ROC curves for the BMI (A), WC (B), LAP (C), VAI (D), red lines-reference line.

\section{Discussion}

Our results indicate the existence of a relation between TDS in men and fat accumulation indicators based on simple anthropometric measurements (BMI, WC, WHR), as well as mathematical algorithms that also take into account the basic parameters of lipid metabolism (LAP, VAI).

Works available in literature primarily describe relationships between indicators based on anthropometric measurements (BMI, WC, WHR) and TT levels in men. Many studies show an inverse correlation between BMI, WHR and WC values and TT concentration, which clearly indicates that excessive fat accumulation, indirectly measured by the above-mentioned anthropometric indicators, is related to hypogonadism [18-25].

Osuna et al. [18] demonstrated that the concentration of TT and SHBG decreases proportionally with the increase in BMI index and the insulin resistance index. In a study similar to ours, Shamim et al. [22] showed that in healthy men aged 30-50 years a decrease in TT concentration accompanied an increase in body weight expressed in the BMI index. The results of our research indicate that this relationship also occurs in the group of men aged 50-75 years. DeFina et al. [26], in a group of 1653 men aged 50-80 years, confirmed a positive correlation between TT concentration and male fitness measured by metabolic equivalents (MET), and statistically and clinically ascertained a negative correlation between testosterone concentration and BMI index value.

Elevated BMI as well as WHR and WC values are associated with metabolic syndrome (MetS), with WC being one of the MetS criteria. Numerous studies show clear associations between MetS 
and age-related hypogonadism. Jaworski et al. emphasized that WC showed a stronger correlation with TDS than with BMI. The results of our research confirmed this observation. In our opinion, waist circumference is definitely a better parameter than BMI to assess obesity and-indirectly-the accumulation of adipose tissue, especially visceral fat. It should be noted that not only adipose tissue contributes to BMI level, as it also reaches higher values in the case of edema or excessive musculature.

There are few studies on the relationship between TT concentration in men and fat accumulation indicators that take into account biochemical parameters (such as VAI or LAP). There is only one publication in available literature assessing the relationship between VAI and hypogonadism [27]. In that study on Chinese men, the authors demonstrated that VAI was the best predictor of hypogonadism among the obesity indicators. This was probably due to the fact that the formula used to calculate VAI includes the greatest number of parameters that are an indirect measure of fat accumulation. Our study, conducted on a different ethnic group, confirmed that men with TDS had significantly higher VAI values. We also showed that higher levels of the LAP index, calculated with two parameters used as MetS recognition criteria, were associated with lower TT concentrations. It is difficult to put this observation in context, as in available literature we did not find any publications examining the relationship between LAP and TDS in men.

Our results showed that higher WHR and WC were associated with lower levels of DHEA-S, suggesting that abdominal obesity contributed to a reduction in this hormone. There is divergent data on this subject in literature. A recent study by Kim et al. on a group of Asian men with impaired glucose tolerance included in a diabetes prevention program did not show any significant relationship between visceral fat and DHEA-S [28]. DHEA-S also did not show a relationship with BMI in a study on Polish males between 20 and 49 years of age [29]. Similar research was conducted by Seyfart T et al. [30], who evaluated the association between sex hormones and anthropometry in a large population-based cohort, and found that testosterone levels were inversely associated with all relevant anthropometric parameters in men. On the other hand, a significant positive relationship between obesity and DHEA-S was demonstrated by Turkish researchers [31]. Their study, however, involved only 37 men. Taking into account the often recommended dehydroepiandrosterone supplementation, it is necessary to further investigate its relationship with obesity in order to draw unambiguous conclusions.

VAI and LAP are currently used as indicators of metabolic disorders, primarily to predict the risk of cardiovascular events. However, our study showed that these indicators, and in particular VAI, may also have diagnostic value in predicting disturbances in serum TT levels in healthy men. Research by Maturana et al. [32] showed that the LAP index may be associated not only with the risk of cardiovascular events (lipid profile, insulin resistance, blood pressure), but also may be related to the concentration of androgens and SHBG and cardiovascular risk factors in postmenopausal women.

It is worth noting that our research was limited by the fact that the respondents volunteered for research after obtaining information about the research program. In the absence of a random selection of the group, our results cannot be generalized, and so we plan to perform similar research on a randomly selected group of patients in the future. The applied diagnostic methods also limited our research. ELISA, which we used in our study, is much less sensitive than RIA in the determination of steroid hormones.

\section{Conclusions}

Fat collection indicators in which biochemical parameters assessing lipid metabolism are also taken into account are better markers of actual body fat deposition than those based only on anthropometric measurements. Considering the proven relationships between adiposity and hypogonadism, they may be important in suspecting and diagnosing testosterone disorders in aging men.

Author Contributions: I.R., A.R., M.L. conceived and designed the experiments; I.R., A.R., K.G. performed the experiments; I.R., A.R., A.S., W.P., A.L. analyzed the data; I.R., O.S.-S., K.P. contributed reagents/materials/analysis tools; I.R., A.R., A.S. wrote the paper. 
Acknowledgments: The authors are grateful to all the patients who participated in this study.

Conflicts of Interest: The authors declare no conflicts of interest.

\section{References}

1. Brand, J.S.; van der Tweel, I.; Grobbee, D.E.; Emmelot-Vonk, M.H.; van der Schouw, Y.T. Testosterone, sex hormone-binding globulin and the metabolic syndrome: A systematic review and meta-analysis of observational studies. Int. J. Epidemiol. 2010, 40, 189-207. [CrossRef] [PubMed]

2. Corona, G.; Monami, M.; Rastrelli, G.; Aversa, A.; Tishova, Y.; Saad, F.; Lenzi, A.; Forti, G.; Mannicci, E.; Maggi, M. Testosterone and metabolic syndrome: A meta-analysis study. J. Sex. Med. 2011, 8, 272-283. [CrossRef] [PubMed]

3. Kelly, D.M.; Jones, T.H. Testosterone: A vascular hormone in health and disease. J. Endocrinol. 2013, 217, R47-R71. [CrossRef] [PubMed]

4. Corona, G.; Vignozzi, L.; Sforza, A.; Mannucci, E.; Maggi, M. Obesity and late-onset hypogonadism. Mol. Cell. Endocrinol. 2015, 418, 120-133. [CrossRef] [PubMed]

5. Cohen, P.G. The hypogonadal-obesity cycle: Role of aromatase in modulating the testosterone-estradiol shunt-a major factor in the genesis of morbid obesity. Med. Hypotheses 1999, 52, 49-51. [CrossRef] [PubMed]

6. Jones, T.H. Effects of testosterone on type 2 diabetes and components of the metabolic syndrome. J. Diabetes 2010, 2, 146-156. [CrossRef] [PubMed]

7. Kelly, D.M.; Jones, T.H. Testosterone and obesity. Obes. Rev. 2015, 16, 581-606. [CrossRef] [PubMed]

8. Blaya, R.; Thomaz, L.D.; Guilhermano, F.; Paludo Ade, O.; Rhoden, L.; Halmenschlager, G.; Rhoden, E.L. Total testosterone levels are correlated to metabolic syndrome components. Aging Male 2016, 19, 85-89. [CrossRef] [PubMed]

9. Hayes, F.J.; Seminara, S.B.; Decruz, S.; Boepple, P.A.; Crowley, W.F., Jr. Aromatase inhibition in the human male reveals a hypothalamic site of estrogen feedback. J. Clin. Endocrinol. Metab. 2000, 85, 3027-3035. [CrossRef] [PubMed]

10. Hayes, F.J.; DeCruz, S.; Seminara, S.B.; Boepple, P.A.; Crowley, W.F., Jr. Differential regulation of gonadotropin secretion by testosterone in the human male: Absence of a negative feedback effect of testosterone on follicle-stimulating hormone secretion. J. Clin. Endocrinol. Metab. 2001, 86, 53-58. [CrossRef] [PubMed]

11. Roseweir, A.K.; Millar, R.P. The role of kisspeptin in the control of gonadotrophin secretion. Hum. Reprod. Update 2009, 15, 203-212. [CrossRef] [PubMed]

12. Isidori, A.M.; Caprio, M.; Stroll, F.; Moretti, C.; Frajese, G.; Isidori, A.; Fabbri, A. Leptin and androgens in male obesity: Evidence for leptin contribution to reduced androgen levels. J. Clin. Endocrinol. Metab. 1999, 84, 3673-3680. [CrossRef] [PubMed]

13. Kahn, H.S. The lipid accumulation product performs better than the body mass index for recognizing cardiovascular risk: A population-based comparison. BMC Cardiovasc. Disord. 2005, 8, 5-26. [CrossRef] [PubMed]

14. Amato, M.C.; Giordano, C.; Galia, M.; Criscimanna, A.; Vitabile, S.; Midiri, M.; Galluzzo, A. Visceral Adiposity Index: A reliable indicator of visceral fat function associated with cardiometabolic risk. Diabetes Care 2010, 33, 920-922. [CrossRef] [PubMed]

15. Bergman, R.N.; Stefanovski, D.; Buchanan, T.A.; Sumner, A.E.; Reynolds, J.C.; Sebring, N.G.; Xiang, A.H.; Watanabe, R.M. A better index of body adiposity. Obesity 2011, 19, 1083-1089. [CrossRef] [PubMed]

16. Kula, K.; Słowikowska-Hilczer, J. Late-onset hypogonadism in men. Endokrynol. Pol. 2012, 63, 15-19.

17. Morley, J.E. Androgens and aging. Maturitas 2001, 38, 61-71. [CrossRef]

18. Osuna, J.A.; Gómez-Pérez, R.; Arata-Bellabarba, G.; Villaroel, V. Relationship between BMI, total testosterone, sex hormone-binding-globulin, leptin, insulin and insulin resistance in obese men. Arch. Androl. 2006, 52, 355-361. [CrossRef] [PubMed]

19. Page, S.T.; Matsumoto, A.M.; Bremner, W.J. DHEA and Testosterone in the Elderly. N. Engl. J. Med. 2007, 356, 635-637. [PubMed]

20. Gapstur, S.M.; Kopp, P.; Gann, P.H.; Chiu, B.C.; Colangelo, L.A.; Liu, K. Changes in BMI modulate age-associated changes in sex hormone binding globulin and total testosterone, but not bio available testosterone in young adult men: The CARDIA Male Hormone Study. Int. J. Obes. 2007, 31, 685-691. [CrossRef] [PubMed] 
21. Paslakis, G.G.; Deuschle, M.M.; Thome, J.J.; Rüße, S.S.; Kopf, D.D. The differential effect of risperidone and olanzapine on insulin sensitivity after 3 weeks of treatment: A HOMA Pilot Study. Pharmacopsychiatry 2012, 45, 96-99. [CrossRef] [PubMed]

22. Shamim, M.O.; Ali Khan, F.M.; Arshad, R. Association between serum total testosterone and Body Mass Index in middle aged healthy men. Pak. J. Med. Sci. 2015, 31, 355-359. [CrossRef] [PubMed]

23. Lopez, D.S.; Qiu, X.; Advani, S.; Tsilidis, K.K.; Khera, M.; Kim, J.; Morgentaler, A.; Wang, R.; Canfield, S. Double Trouble: Co-occurrence of testosterone deficiency and body fatness associated with all-cause mortality in US men. Clin. Endocrinol. 2018, 88, 58-65. [CrossRef] [PubMed]

24. Jaworski, P.E.; Ramos, A.; Nicoleit, A.R.; Bacarin, L.F.; Neto, P.O. Importance of abdominal circumference and body mass index values in predicting male hypogonadism-A practical approach. Arch. Endocrinol. Metab. 2017, 61, 76-80. [CrossRef] [PubMed]

25. Yassin, A.A.; Nettleship, J.E.; Salman, M.; Almehmadi, Y. Waist circumference is superior to weight and BMI in predicting sexual symptoms, voiding symptoms and psychosomatic symptoms in men with hypogonadism and erectile dysfunction. Andrologia 2017, 49, e12634. [CrossRef] [PubMed]

26. DeFina, L.; Radford, N.; Leonard, D.; Howard, E.; Wilson, R.; Cooper, T.; Clark, M.; Gruntmanis, U. Testosterone level in men correlates with BMI and cardiorespiratory fitness but is not related to age. Endocr. Abstr. 2015, 37, EP144. [CrossRef]

27. Wang, N.; Zhai, H.; Han, B.; Li, Q.; Chen, Y.; Chen, Y.; Xia, F.; Lin, D.; Lu, Y. Visceral fat dysfunction is positively associated with hypogonadism in Chinese men. Sci Rep. 2016, 6, 19844. [CrossRef] [PubMed]

28. Kim, C.; Dabelea, D.; Kalyani, R.R.; Christophi, C.A.; Bray, G.A.; Pi-Sunyer, X.; Darwin, C.H.; Yalamanchi, S.; Barrett-Connor, E.; Golden, S.H. Changes in Visceral Adiposity, Subcutaneous Adiposity, and Sex Hormones in the Diabetes Prevention Program. J. Clin. Endocrinol. Metab. 2017, 102, 3381-3389. [CrossRef] [PubMed]

29. Jastrzębska, S.; Walczak-Jędrzejowska, R.; Kramek, E.; Marchlewska, K.; Oszukowska, E.; Filipiak, E.; Kula, K.; Slowikowska-Hilczer, J. Relationship between sexual function, body mass index and levels of sex steroid hormones in young men. Endokrynol. Pol. 2014, 65, 203-209. [CrossRef] [PubMed]

30. Topsakal, S.; Akin, F.; Yerlikaya, E.; Erurker, T.; Dogu, H. Dehydroepiandrosterone sulfate levels in Turkish obese patients. Eat. Weight Disord. 2014, 19, 261-265. [CrossRef] [PubMed]

31. Seyfart, T.; Friedrich, N.; Kische, H.; Bülow, R.; Wallaschofski, H.; Völzke, H.; Nauck, M.; Keevil, B.G.; Haring, R. Association of sex hormones with physical, laboratory, and imaging markers of anthropometry in men and women from the general population. PLoS ONE 2018, 13, e0189042. [CrossRef] [PubMed]

32. Maturana, M.A.; Moreira, R.M.; Spritzer, P.M. Lipid accumulation product (LAP) is related to androgenicity and cardiovascular risk factors in postmenopausal women. Maturitas 2011, 70, 395-399. [CrossRef] [PubMed] 